\title{
Visual Impact Analysis of Large Urban Investments on the Cityscape
}

\author{
Klara Czyńskal \\ ${ }^{1}$ West Pomeranian University of Technology, Szczecin, Poland \\ ${ }^{1}$ kczynska@zut.edu.pl
}

\begin{abstract}
The article presents the assessment method for large (horizontally spread) urban investment and its visual impact on the cityscape using digital analyses. The visual impact assessment is often used in relation to facilities which dominate in the cityscape, mainly tall buildings. Various studies, however, examine the impact of wide but relatively low-rising buildings and their impact on the cityscape. The article presents a methodology for the assessment of the visual impact and a case study for a building facility comprising several tightly developed and medium height blocks of buildings in a city center of a significant historical value in Gdańsk, Poland. The research has been based on the Visual Impact Size method (VIS) and a city model consisting of a regular cloud of points (Digital Surface Model). The simulation has been developed using a dedicated $C++$ software (developed by author). The study aimed at assessing the following: a) to what degree such an urban investment can influence the cityscape; b) how the impact can be analyzed using digital techniques, and c) what input parameters of the analysis are crucial for satisfactory accuracy of its results.
\end{abstract}

Keywords: digital cityscape analysis, urban skyline, large urban investments, visual impact, VIS method

\section{INTORDUCTION}

The area of the Gdańsk Shipyard is very special in the Polish history. There the collapse of communism in Poland started. Today, thirty years after the system transformation and the collapse of the shipbuilding industry, the location is an attractive investment site designated for intensive development of tall buildings in the city center. Buildings planned (including tall ones) will provide major transformation of the area, as well as the cityscape of Gdańsk. Considering the ongoing discussion on the future of that area, which involves the historical conservation ser- vice, the City and investors, the area is interesting for research. The cooperation with the investor (Atrium Sp. $z$ o. o.) produced a study aimed at verifying the visual impact of buildings planned.

The article describes research implemented to verify the impact of new buildings, which are relatively low-rising but wide spread, on the historical cityscape. The literature on the topic describes research that focus on the impact of individual architectural forms on the cityscape (individual tall building or group of such buildings). The visual impact analysis of a horizontally wider development is a more 
complex process. The development of the methodology used to examine the impact of such a development has potentially large application and importance for further scientific research (Czyńska, Rubinowicz 2019).

\section{VIS METHOD AND 3D CITY MODEL}

The study uses the VIS method (Czyńska 2015) which enables to simulate the visibility of a building and its domination in the cityscape (Rød, van der Meer 2009). Results are presented in the form of a map reflecting simultaneously the two parameters. The location of a building is usually defined by a single control point or a set of several points. This enables to reflect the body of the building more accurately (Caha 2017). Analyses presented in the article indicate the possibility of expanding the VIS method with analysis of large urban investments by using much larger number of control points (>100) precisely corresponding to the body of a given facility. According to the VIS method, for every point in the city, the emulation of the visual impact map requires to set the maximum height which is a geometrical visibility range, above which a building can be seen. Comparing with other studies (Czyńska 2015; Caha 2017), the study in question support a more complete analysis of the impact of large urban investments.

Although the result has a continuous nature, i.e. the calculation leads to precise limit height values, the interpretation of findings is better once we limit the number of thresholds (depending on height of individual building). Usually, it is 8 to 10 different heights every $20 \mathrm{~m}$. It depends, however, on the specific nature of the facility in question and the required precision of calculation. This produces an aggregated representation of the visual impact of a building that can be seen from specific thresholds. Results can be displayed in various ways - projections, axonometric views and perspectives or 3D rendering. In practical terms, a map with colors marking the exposure of a given building in the city is the best for the interpretation of the results.

The study presented in the article is based on Digital Surface Model (DSM) and Digital Terrain Model (DTM), which are derived from LIDAR data. Such models are available to the public for the entire area of Poland. They are provided by the Head Office of Geodesy and Cartography. Data have been collected under the flood protection project of ISOK in 2013 (figure 1). The cloud of points, which comprises digital models, contains all landscape components, such as buildings, tall green, technical infrastructure, bridges and flyovers, all reflected with the same precision. DSM model, used for the purpose of the study, has mesh density of $0.5 \mathrm{~m}$. This enables creating a precise picture of the city space. It was also very important to include tall green, which significantly reduces the visual impact (Rubinowicz 2018). A specialist C++ software is used to generate the VIS simulation (Rubinowicz 2017). It has been optimized for enhancing the efficiency of processing data representing a digital picture of the city space. Although the study uses the dedicated software, it is possible to conduct a similar process based on a standard specialist GIS software as well. In this case, the complexity of calculations due to the size of input data and computation time can be a limitation.

\section{SIMULATION PROCESS}

The analysis of the visual impact focused on a planned group of densely developed facilities in the northern part of Gdańsk, Poland (figure 1). Although the expected height of buildings is $33 \mathrm{~m}$, the investor considered increasing that height in some parts of the development. Due to a variety of architectural forms in the vicinity and quite extensive nature of space, it was important to examine the impact of the new development on the cityscape within the largest range possible.

An important component of the study was the deployment of control points within the area concerned, as a basis for VIS calculations. Because of the size of the investment the decision was made to cover the entire area evenly with control points, with special focus on points in corners and perimeters of buildings planned. Finally, 154 points were set for 
Figure 1

DSM Gdańsk

visualization used

for visual impact

analysis. Blue is

used to mark

planned group of

buildings in

question. Source:

fig. by author

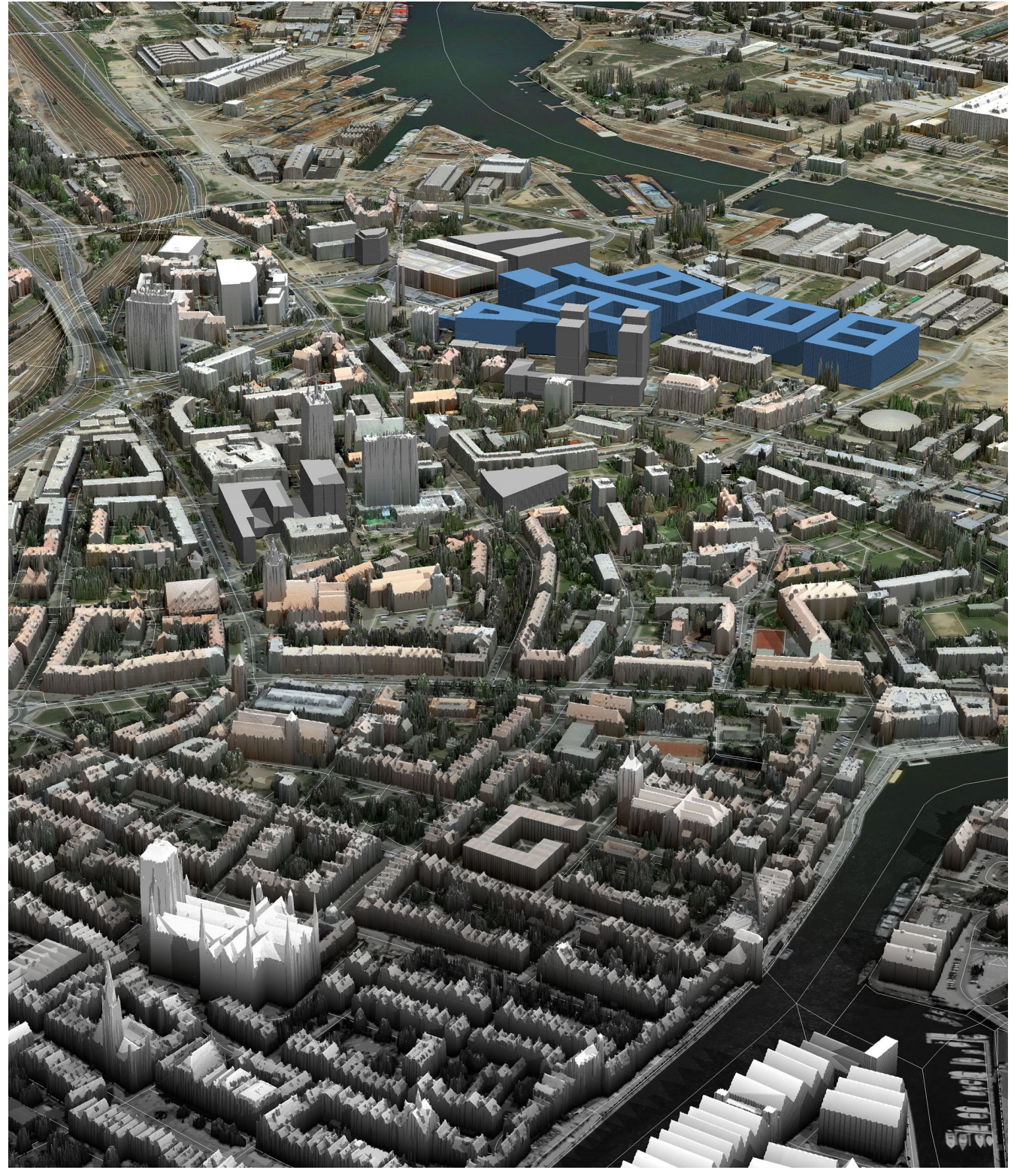

Data - CITY INFORMATION MODELLING AND GIS - Volume 3 -

eCAADe 37 / SIGraDi 23 | 299 
which a visual impact map was developed (figure 2). Thus, the map included the impact of virtually every section of the investment plot on the cityscape.

The analysis covered an area of $25 \mathrm{~km} 2(5 \times 5 \mathrm{~km})$. The accuracy of the result was also important and it depended on a number of parameters: a) precision and validity of the model which encompasses al components of the actual urban space, including a) trees; b) VIS analysis using a number of control points which depends on the type of a facility, c) analysis that preserves the resolution of the model and precision of VIS analyses.

The above objectives for the calculation process turn it into a time-consuming and complex operation. Results in figure 1 are the effect achieved by using software developed by the author (see 'Acknowledgment'). The DSM model used had top possible precision was ensured by the 3D-Mesh vector model (Rubinowicz 2019). The accuracy of VIS computation is $10 \mathrm{~cm}$. Results guarantee convergence with the future visual impact of the investment.

\section{RESULTS}

The VIS analysis for the large horizontal development has proved its major visual impact in space. The impact is not only the result of its height but also the width of the visible part of the investment (expressed by many control points). The VIS map indicated several areas of strong exposure of the investment, including areas of major cultural value that are important for the cityscape. The domination of the planned development in space is reflected by four main height thresholds set every $10 \mathrm{~m}$. In the VIS map (figure 3), those thresholds are marked by different colors (red, orange, dark and light yellow). Therefore, the VIS map provides information about the visibility range of buildings (whole and in part). The study also took into consideration other height levels up to $70 \mathrm{~m}$. Those are presented using less vivid semitransparent colors.

The figure (figure 3) includes impact zones which, despite a limited height of the development, virtually cover the whole area examined (25 km2).
The main visual impact of the investment focuses in the vicinity of investment site of less intensive industrial development. It is also significant in areas near the rivers of Motława and Martwa Wisła, as well as on the other river bank, including the Ostrów Island. Southward, where the intensity of buildings is higher in the city center, the visual impact of buildings planned is smaller and does not cause major spatial deformation.

Major observation points for the new buildings are located at heights of Wysoczyzna Gdańska. One of them is the popular Gradowa Hill (C-20 in fig. 3). To facilitate conclusions, the VIS method was used to develop a number of simulations showing new buildings in their urban context. New buildings can be seen together with historical facilities of Gdańsk in the vista from the Gradowa Hill (figure 4). Results show a need for further studies and adjustment of the investment to reach its proper and harmonious integration with valuable vistas in Gdańsk.

\section{DISCUSSION}

The literature provides few examples of visual impact studies focusing on horizontally spread architectural forms. Caha (2017) presented research which enhanced precision of viewshed results by a better shape projection of a given facility. In the case of elongated architectural forms, a number of test points have been used, for which a cumulative viewshed has been calculated. A similar solution was used by the author in her study of the tall Hanza Tower in Szczecin (Czyńska 2018). Interesting research was also implemented by Garcia (2015) for historical area in Spanish cities while examining visibility using angular values and distance.

As Fisher rightly noticed in 1991, viewshed results depend very much on the quality of input data. In the case of cityscape studies, input data, or 3D models, are crucial for a desired precision of the result. Too little precision of the DSM model (mesh in excess of $0.5 \mathrm{~m}$ ) influences the quality of the result (Bishop, 2003). A simplified structure or geometry of CAD and CityGML models also reduces the accu- 
Figure 2

Distribution of 154

control points

within investment

site used for visual impact analysis

(VIS). Source: fig. by author

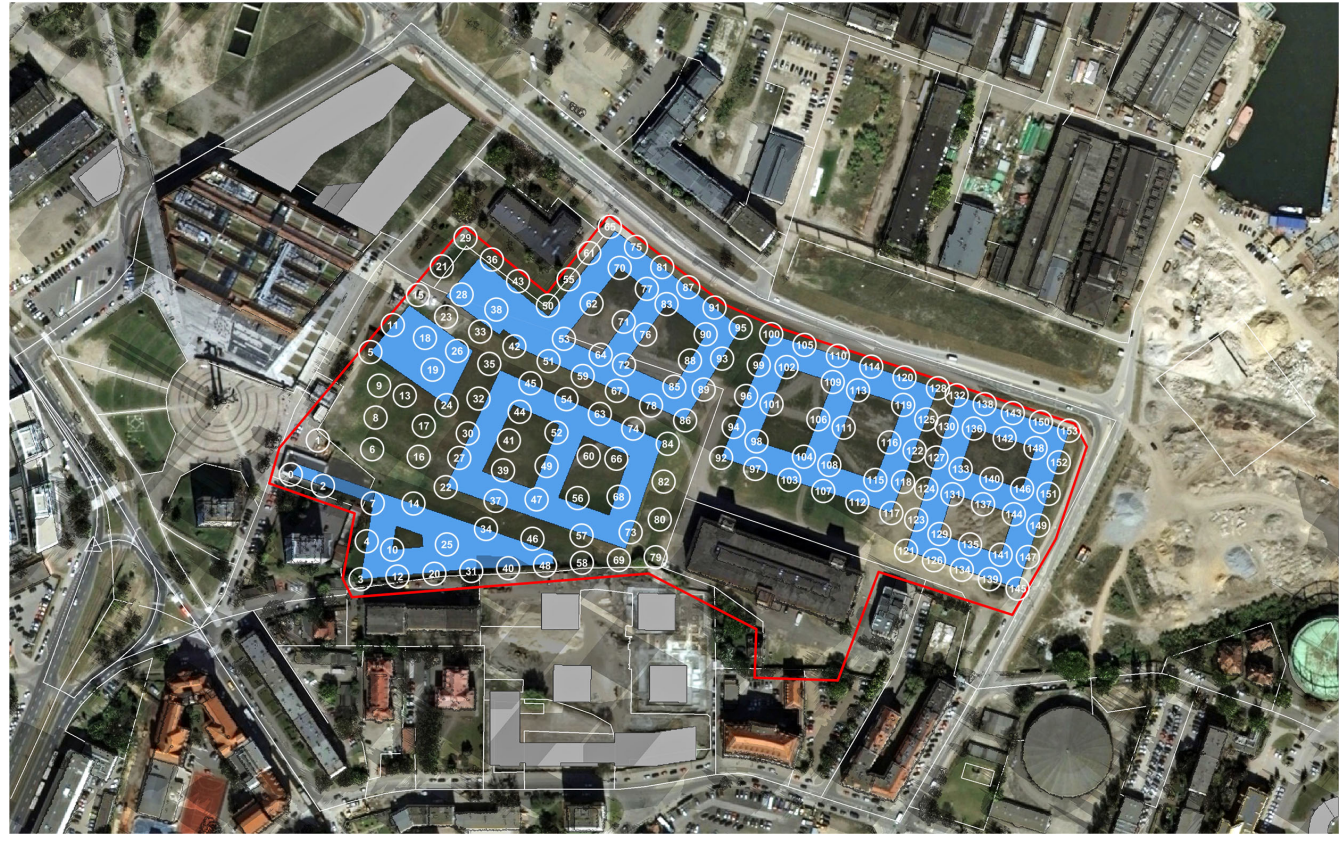

racy of the result. A large analysis area in combination with high resolution of the DSM model can be a challenge for a computer. Therefore, it is necessary to optimize the algorithm applied for VIS calculations. Software applied in the study enables the emulation of the visibility field for an individual test point within $1.0 \mathrm{~km} 2$ and a mesh size of $0.5 \mathrm{~m}$ during approx. 48 $\mathrm{s}$ ( 4 core processor and 32GB RAM). The study always includes the full resolution of a DSM model. The precision of the model has relatively minor impact on the simulation time.

\section{CONCLUSIONS}

The study has proven the possibility of using the VIS method to analyze the visual impact of large urban investments in a city. The case study of Gdańsk has shown that such facilities may have a major impact on the cityscape. VIS maps enable to define precisely the range and scale of visibility for any new building planned. Therefore, it improves the planning and designing process to make new investment more integrated with important urban vistas.

The analysis of large urban investments is possible when we use a larger number of control points which precisely reflect the location and shape of new buildings. The more control points are used in the VIS analysis, the more precise is the result. This, however, increases the length and complexity of the calculation process.

Validity and resolution of the DSM model significantly influences the precision of VIS analyses. He resolution of the mesh $(0.5 \mathrm{~m})$ enables to reflect the important is the precision of the calculation process which depends on the software. The study was based on $\mathrm{C}++$ software developed by the author, which helped to reach the precision of the VIS analysis of up to $10 \mathrm{~cm}$. $3 \mathrm{D}$ space of a city as a basis for calculation. Equally 


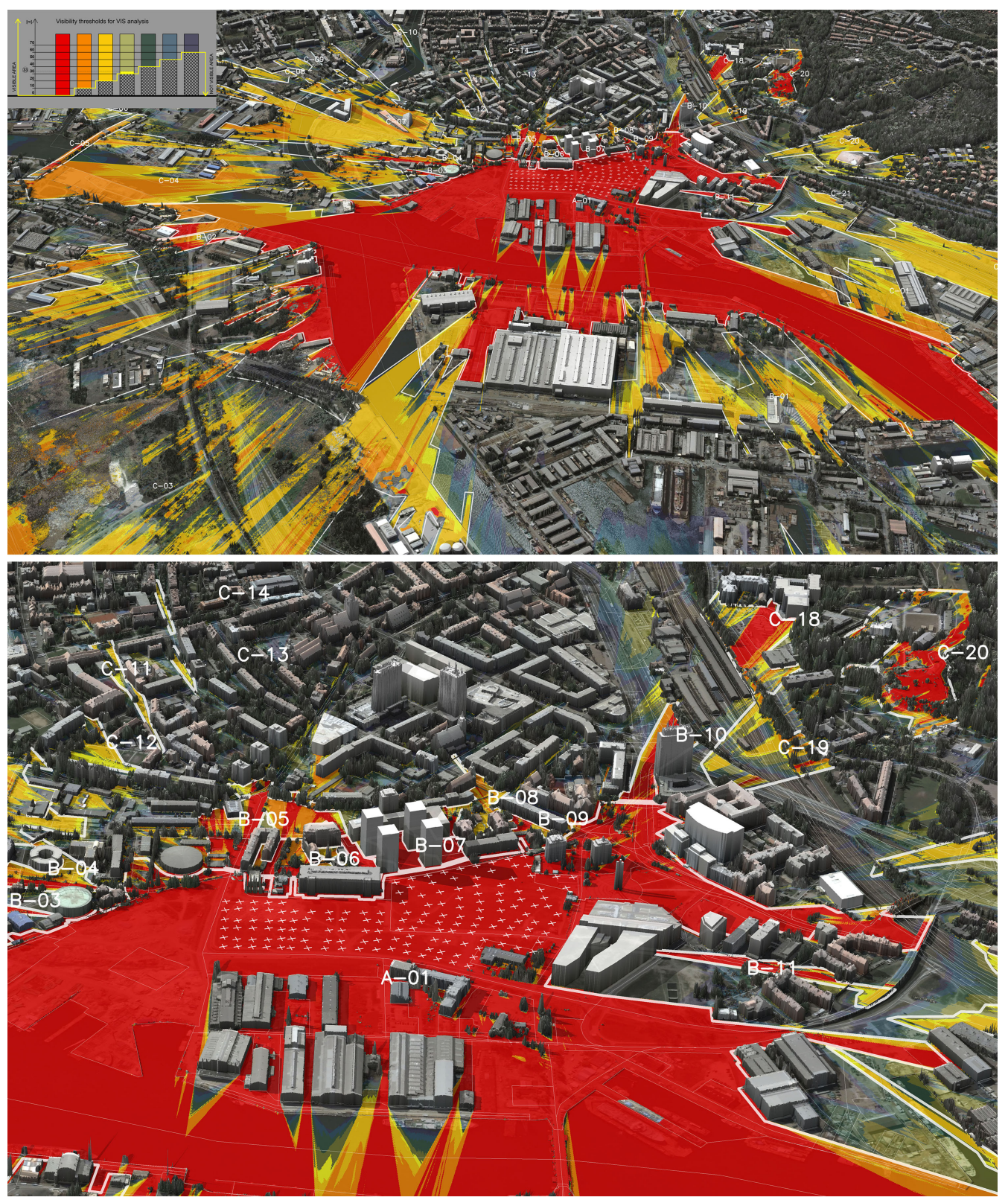

Figure 3

Visual impact

analysis of large

urban investment

with the use of VIS

method: 154

control points set

for analyses to

include the impact

of every section of the investment plot on the cityscape.

Colors shows the scale of visibility and dominance of new buildings in space. Source: fig. by author

302 | eCAADe 37 / SIGraDi 23 - Data - CITY INFORMATION MODELLING AND GIS - Volume 3 
Figure 4

Simulations of new buildings (blue) in their spatial context - view generated from DSM model combined with photograph. Source: fig. by author
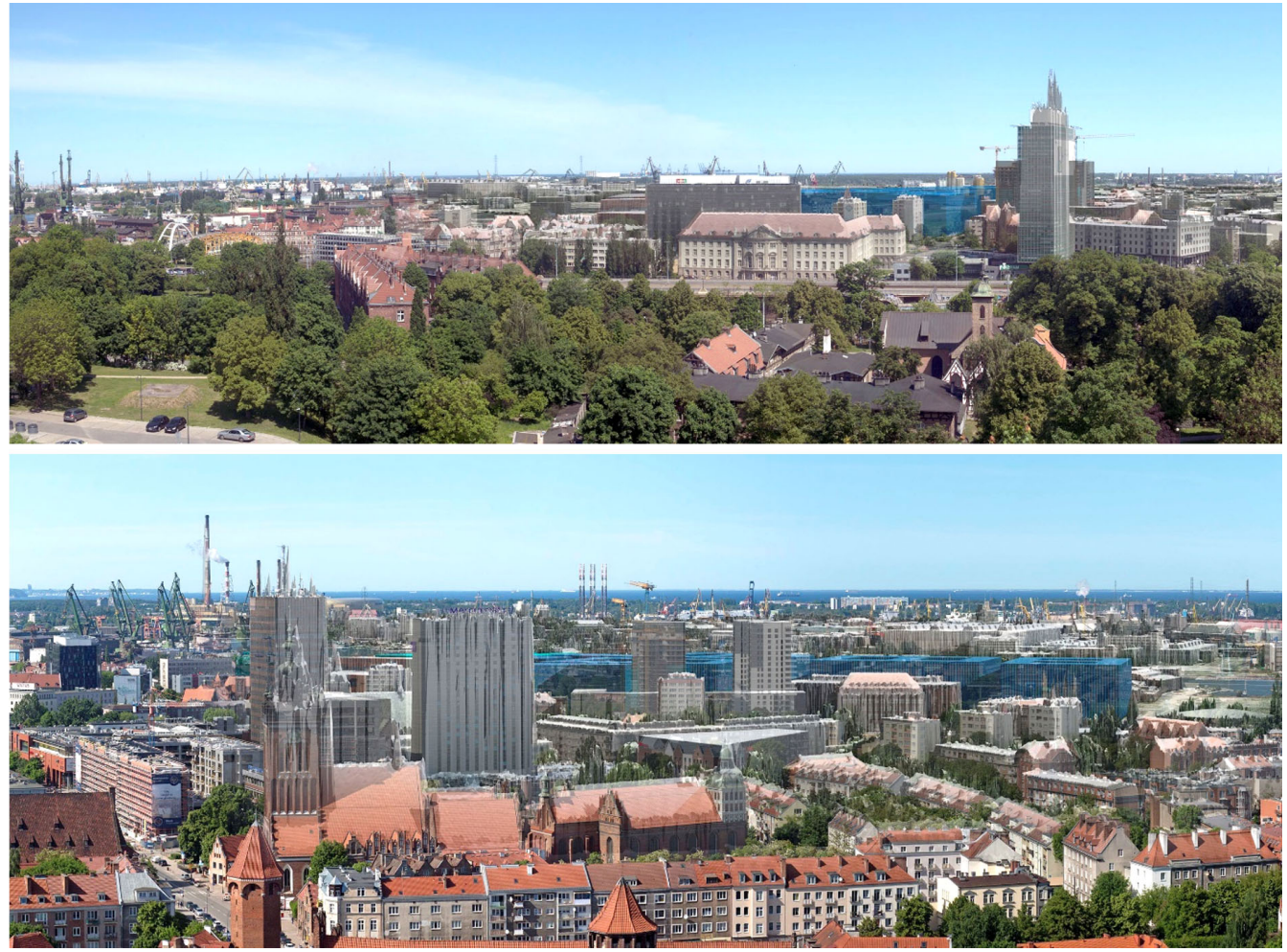

The VIS method has a tremendous potential and has bene used in the planning practice in several cities in Poland to analyze tall buildings. The study presented in this article widened the application scope of the method with large urban investments. Results of visual analyses may facilitate protection and development of the cityscape, in particular in historical cities. It enables to predict spatial impact of new buildings. The VIS may also be applied for comprehensive and harmonious planning of the contemporary city skyline.

\section{ACKNOWLEDGEMENTS}

$\mathrm{C}++$ software used for the studies described in the article was developed by Paweł Rubinowicz PhD., an ar- chitect (West Pomeranian University of Technology, Szczecin, Poland). The author of the article has collaborated while developing the VIS algorithm.

\section{REFERENCES}

Bishop, I. D. 2003, 'Assessment of visual qualities, impacts, and behaviours, in the landscape, by using measures of visibility', Environment and Planning B: Planning and Design, 30, pp. 677-688

Caha, J. 2017, 'Representing buildings for visibility analyses in urban spaces', in Ivan et al., I. (eds) 2017, Dynamics in Glscience, Lecture Notes in Geoinformation and Cartography, Springer International Publishing, pp. 17-29

Czyńska, K. 2015, 'Application of Lidar Data and 3dCity Models in Visual Impact Simulations of Tall 
Buildings', International Archives of the Photogrammetry Remote Sensing and Spatial Information Science, 47(W3), pp. 1359-1366

Czyńska, K. 2018 'High precision visibility and dominance analysis of tall building in cityscape - on a basis of Digital Surface Model', Proceedings of the 36th eCAADe Conference 2018, Łódź, Poland, pp. 481-488

Czyńska, K. and Rubinowicz, P. 2019, 'Classification of cityscape areas according to landmarks visibility analysis', Environmental Impact Assessment Review, 76, pp. 47-60

Fisher, P. F. 1991, 'First experiments in viewshed uncertainty: the accuracy of the viewshed area', Photogrammetric Engineering and Remote Sensing, 57, pp. 1321-1327

García, S. and Rodríguez, M. 2015, 'A geospatial indicator for assessing urban panoramic views', Computers, Environment and Urban Systems, 49, pp. 42-53

Rubinowicz, P. 2017, 'Generation of CityGML LoD1 city models using BDOT10K and LiDAR data', Space \& Form, 31, pp. 319-341

Rubinowicz, P. 2018 'Application of Available Digital Resources for City Visualisation and Urban Analysis', Proceedings of the 36th eCAADe Conference 2018, Łódź, Poland, pp. 595-602

Rubinowicz, P. 2019 'Visualisation of DSM as 3D-Mesh for Urban Analyses', Proceedings of the 18th International Conference on Geometry and Graphics, 40th Anniversary - Milan, Italy, Milan, Italy, pp. 1013-1022

Rød, J. K. and van der Meer, D. 2009, 'Visibility and dominance analysis: Assessing a high-rise building project in Trondheim', Environment and Planning B: Planning and Design, 36(4), pp. 698-710 